\title{
Wear Properties of Hot Extruded Aluminum Powder Compacts
}

\author{
Mohammed Y. Abdellah', M. Mahmoud Moustafa'2, Ashraf T. Mohamed2,3, \\ G. T. Abdel-Jaber ${ }^{1}$ \\ ${ }^{1}$ Mechanical Engineering Department, Faculty of Engineering, South Valley University, Qena, Egypt \\ ${ }^{2}$ Production and Design Department, Faculty of Engineering, Minia Universities, Minya, Egypt \\ ${ }^{3}$ Mechanical Engineering Department, Al Baha University, Al Bahah, KSA \\ Email: mohammed yahya42@yahoo.com
}

Received 6 May 2014; revised 16 June 2014; accepted 26 July 2014

Copyright (C) 2014 by authors and OALib.

This work is licensed under the Creative Commons Attribution International License (CC BY). http://creativecommons.org/licenses/by/4.0/

(c) (i) Open Access

\section{Abstract}

Aluminum powder compacts have low wear resistance due to the reduction in ductility. The ductility enhances using the metalwork technology like the hot extrusion process. The wear test is done using pin on disc machine for all hot extruded aluminum compacted specimen reinforced with $1,2,3$, and 4 copper wires, and extruded at $450^{\circ} \mathrm{C}$. The load is applied by dead weights $(1600$ gm) at 4 variable linear velocities of $0.628,0.942,1.25$ and $1.57 \mathrm{~m} / \mathrm{sec}$ at constant time. The results shown that wear resistance enhances with the hot extrusion process for increasing number of reinforcement copper wires.

\section{Keywords}

Wear Resistance, Aluminum Compacts, Pin on Disc, Hot Extrusion

Subject Areas: Engineering, Mineral Engineering

\section{Introduction}

Metal matrix reinforced with strength reinforcements has a considerable attention because of their superior properties in comparison with most of monotonic materials [1]-[3].

In last year's, metal matrix composites (MMCs) give an observed development in many industry branches, among others in the automotive, aircraft industry, and electrical engineering and electronics ones, as well as in armaments, etc. [4]-[6]. Three forms of reinforcing shape for metal matrix composite fiber particles and dispersions [7] [8].

Various types of aluminum based composites can be related to the advantage of powder metallurgy which results in specific advantages of aluminum and its alloys such as light weight, corrosion resistance, non-magnetic 
characteristics, and high thermal and electrical conductivities, Extrusion process is assumed [9] to be reasonable when combined with powder metallurgical method. Mostly, extrusion can be defined as an act of ejection of metal by mechanical force [10] through well defined opening geometries. Mainly, to give a suitable degree of softness and plasticity, the metal is heated in a hot working operation. Various types of aluminum based powder metallurgical composite can be developing with this metal working process [9].

Improvement of densification and hence mechanical properties for powder metallurgical process can be achieved with size reduction which is widely, performed with hot extrusion process. Thus, the compacted product can be implemented in structural applications [11] [12]. Other than the application to alloy powders or pure metal is limited [13]. Both the adhesive and abrasive resistance has been improved with the addition of hard particles to aluminum powders [14]-[16]. Delgado et al. [17] investigated Rotating sliding wear on TiB2-B4C at room temperature, the experimental results reported that the sliding velocity affects both friction coefficient and wear rate values of TiB2-B4C ceramics.

\section{Experimental Work}

\subsection{Material Behavior and Characterization}

A commercial aluminum metal powder with a mean size of 80 grit/inch supplied by ADWIC code number 8010075, molecular weight of 26.98 is used for all specimens as a matrix (base material). Figure 1 shows the powder particles shape. The aluminum powder matrix is combined with copper wires of $2 \mathrm{~mm}$ constant diameter as reinforcement material; Table 1 shows the mechanical properties of the used copper wires.

The compaction process is carried out on the compaction set up shown in Figure 2. The compaction velocity was $5 \mathrm{~mm} / \mathrm{min}$. The process continues to the maximum compaction load value then the load is released. The details of the manufacturing process are not the study case. Figure 3 shows arrangement of copper wires in the compacted specimen product.

\subsection{Wear Test}

The wear test is performed on specimens that compacted at $15 \mathrm{~mm} / \mathrm{min}$ and also on hot extruded billet at $450^{\circ} \mathrm{C}$ to compare the enhancement rate. The test is carried out using Pin-on-Disc wear device, the general view of the

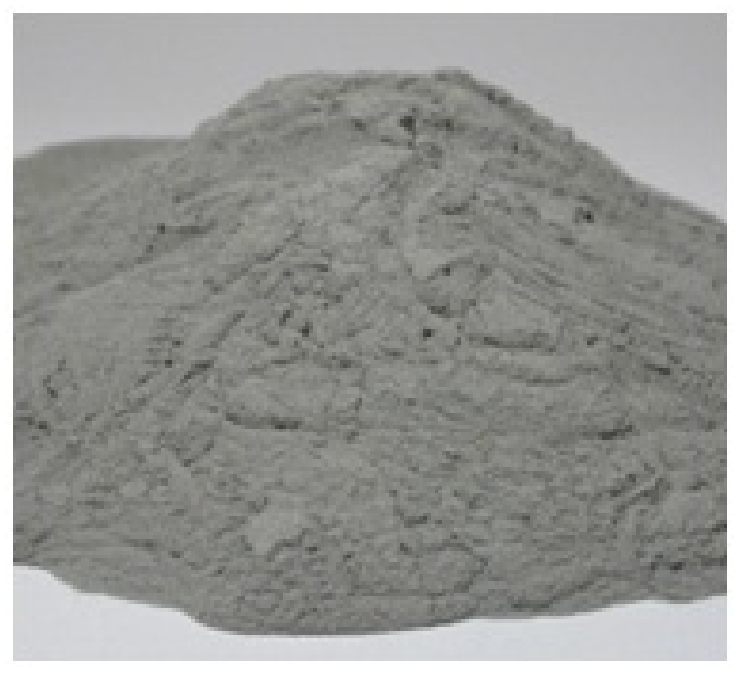

Figure 1. Photograph illustrate powder particles [18].

Table 1. Mechanical properties of the tested materials.

\begin{tabular}{cccccc}
\hline Test material & Compaction velocity & $\begin{array}{c}\text { Yield strength, } \\
\text { MPa }\end{array}$ & Ultimate strength & $\begin{array}{c}\text { K } \\
\text { Material Coef. MPa }\end{array}$ & $\begin{array}{c}\text { Hardening exponent } \\
n,-\end{array}$ \\
\hline Aluminum & 5 & 65.699 & 80.211 & 101 & 0.068 \\
Copper reinforcement & 87.631 & 176.842 & 255 & 0.175 \\
\hline
\end{tabular}




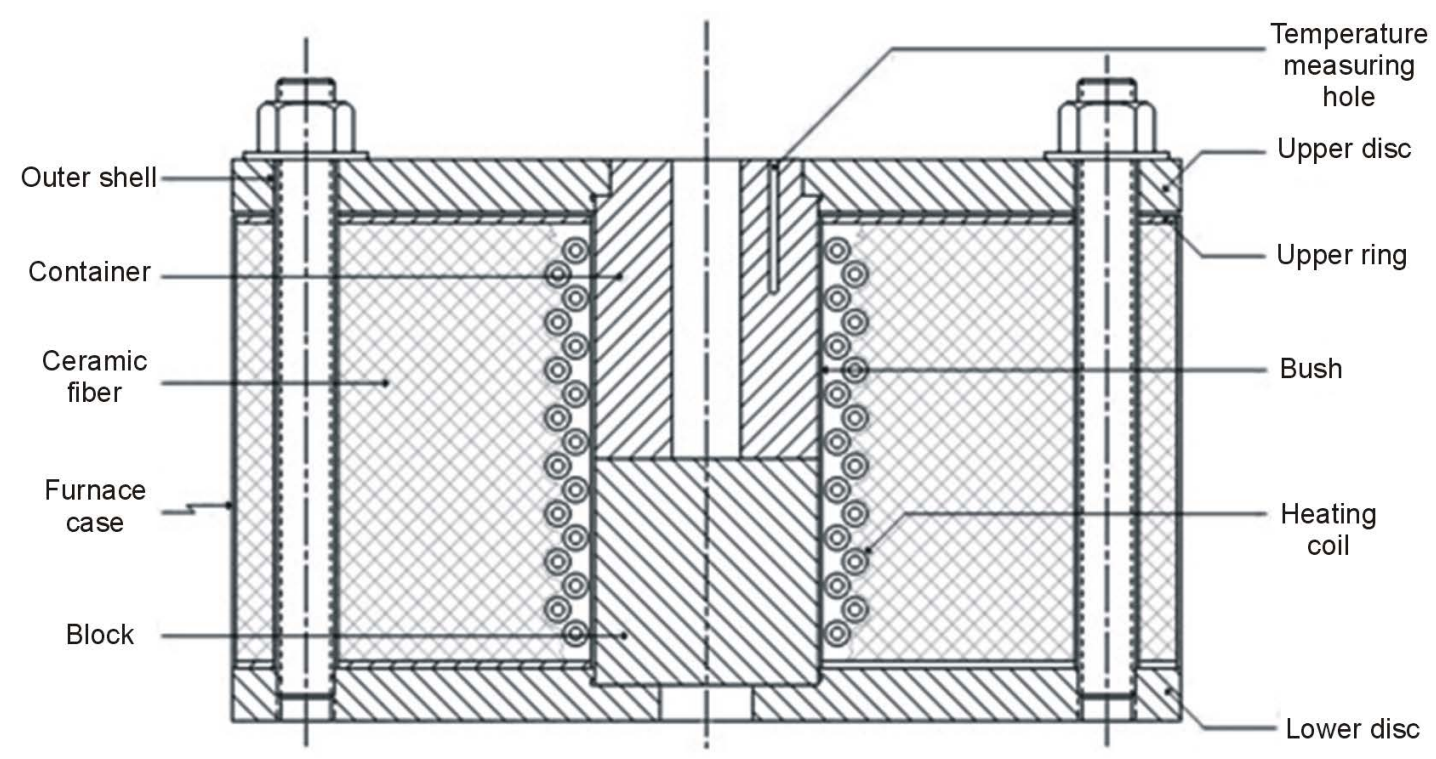

Figure 2. Schematic drawing of the compaction apparatus.

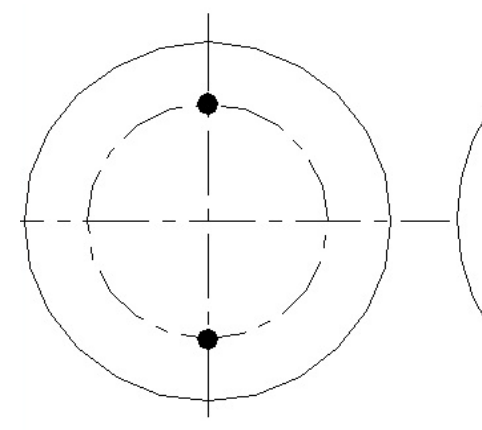

(a)

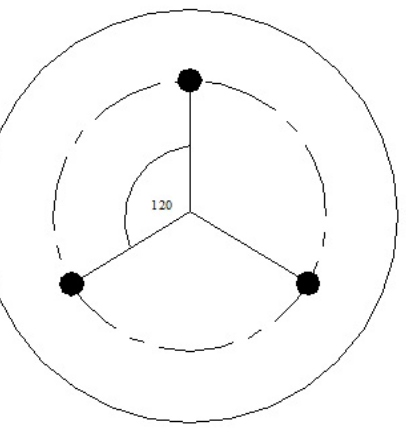

(b)

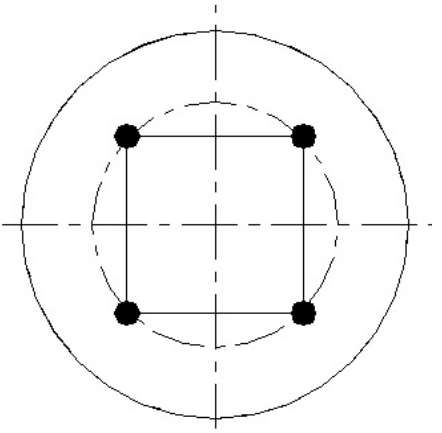

(c)

Figure 3. Arrangement of reinforcement wires: (a) 2-wires; (b) 3-wires and (c) 4-wires.

wear test device is shown in Figure 4. It consists of a rotary horizontal steel disc driven by variable speed motor. The test specimen is held in the specimen holder that fastened to the loading lever against the rough counterface. Through two thin spring steel sheets, where strain gauges are adhered, friction coefficient can be measured. The load is applied by dead weights (1600 gm) at 4 variable linear velocities of $0.628,0.942,1.25$ and $1.57 \mathrm{~m} / \mathrm{sec}$ at constant time. The contact surface of the test specimens was polished by an emery paper before the test. The counterface is in the form of an emery paper of 80 grad attached on a steel disc of $50 \mathrm{~mm}$ inner diameter and $100 \mathrm{~mm}$ outer diameter with $2 \mathrm{~mm}$ thickness.

\section{Result and Discussion}

\section{Wear of Un-Extruded Compacted Specimen}

Commonly, in Figure 5, the wear resistance decreases with increasing sliding velocity for constant time. Compaction pressure is obtained by pressing from one side only, so the greatest density exists in the top layer just below the movable punch and beside container walls, therefore three dependent results can be taken. Increasing density of the surface layer causes an increasing in surface hardness, which increases the wear resistance at the beginning of the test (lower sliding linear velocity), while at next velocities this layer is decreasing in density and hardness so wear resistance decreases with the increase of velocity. Figure 6 shows density distribution. Although, the wear resistance is returned to increase at the third velocity $(1.25 \mathrm{~m} / \mathrm{sec})$ for specimens reinforced by 1 -wire and that of 2-wires, while for those reinforced by 3 -wires and 4 -wires this increase is shifted to the 


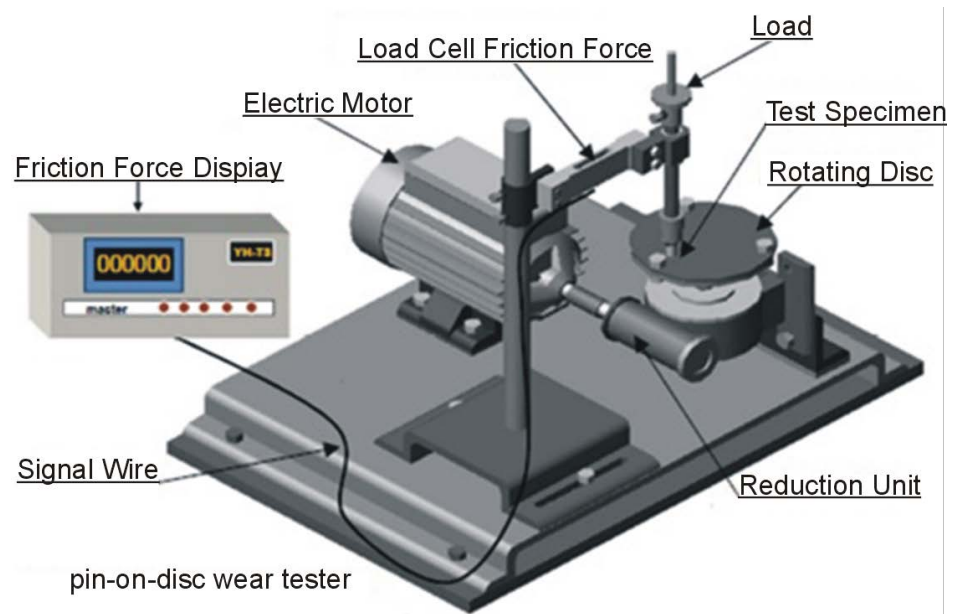

Figure 4. Pin-on-disc wear tester [19].

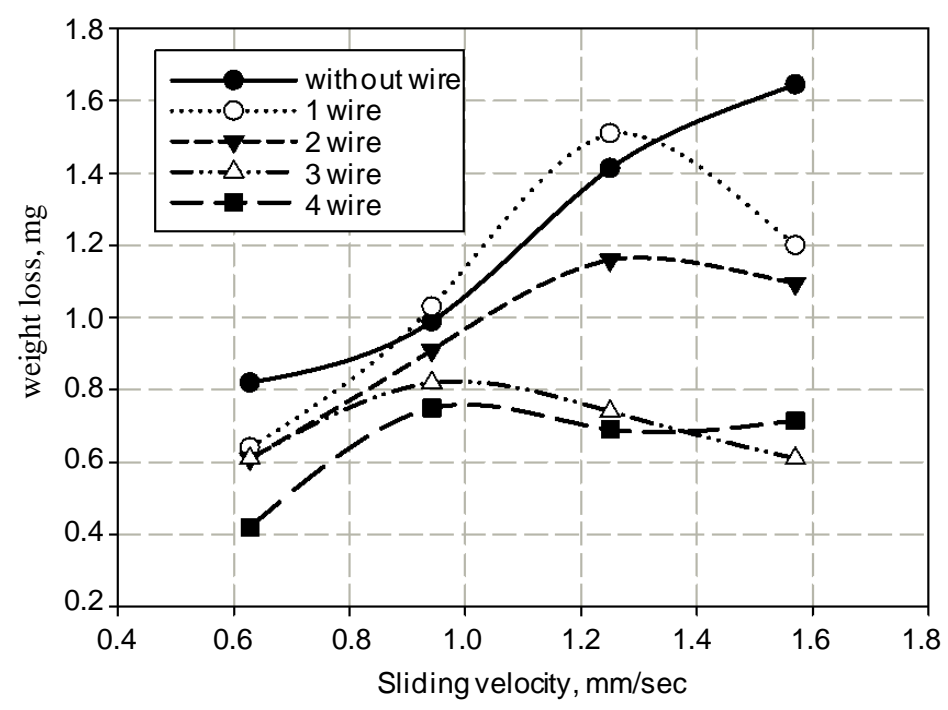

Figure 5. Wear resistant variation with different number of reinforcement wires.

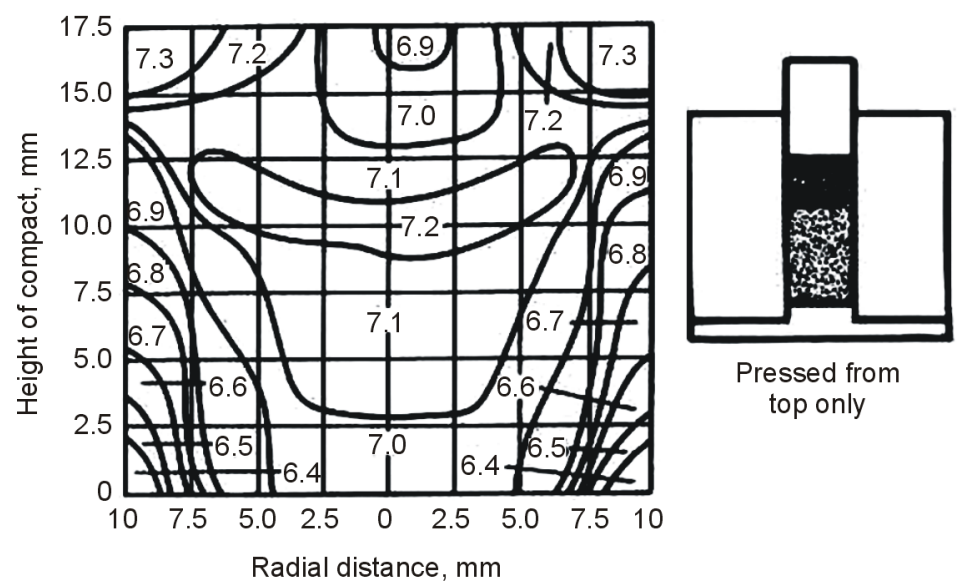

Figure 6. Basic green density distribution for single end dies compaction [20]. 
second velocity $(0.942 \mathrm{~m} / \mathrm{sec})$. This is owing to that for the first group the contact layer is more bonding and hard (Table 2), so it takes more time to be removed then the contact will be directly on the reinforcement while in the second group this layer is less hard and bonding so it is fast removed. For the same velocity it is clear that increasing reinforcement number increases wear resistance (less weight loss) especially at low velocity, while deviation occurred in the higher ones, this is due to lack of densification which makes rarefaction, which occurred by reinforcement (see Figure 7). Extrusion process gives enhancement to wear resistance as shown in Figure 8, this attributed to that hot working results in a rapid diffusion, which aids in decreasing the chemical inhomogeneities of compacted billets. Blowholes and porosity are eliminated by the welding together of these cavities, and the coarse columnar of the billets are broken down and refine into smaller equiaxed recrystallized grains. These changes in structure from hot working result in an increase in ductility, toughness and strength.

Table 2. Vickers hardness numbers for all the produced specimens.

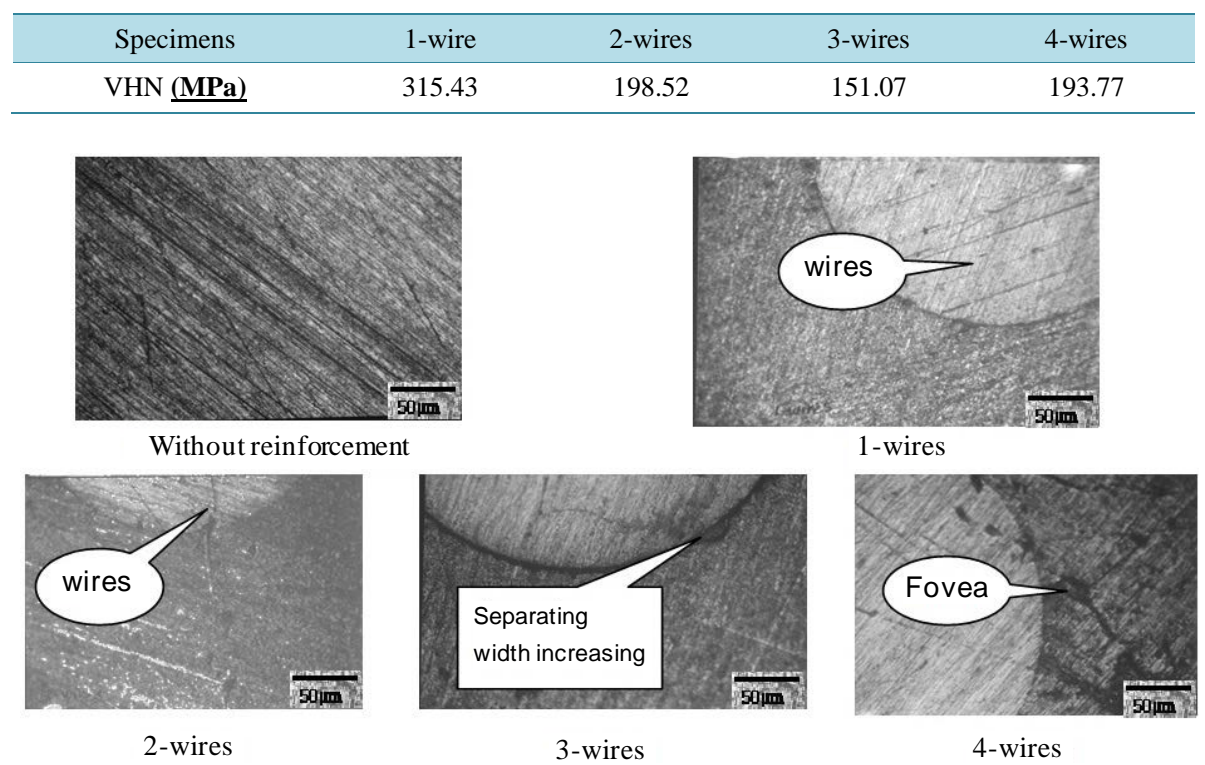

Figure 7. Macrostructure of the produced aluminum metal matrix composites at $15 \mathrm{~mm} / \mathrm{min}$.

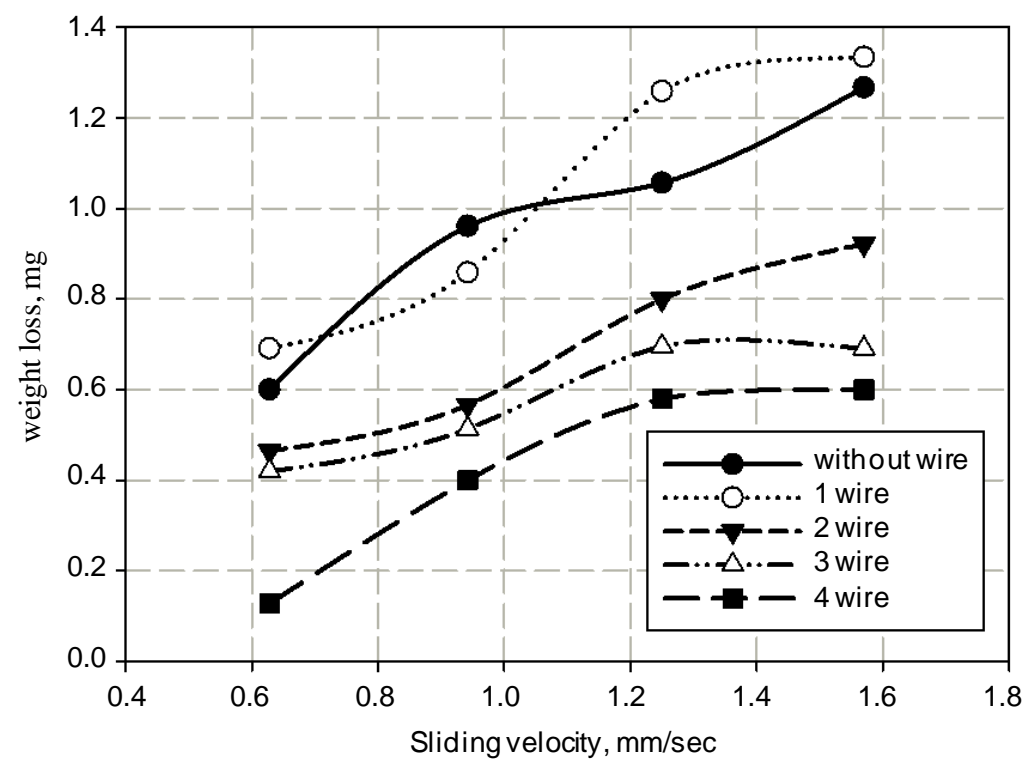

Figure 8. Wear resistance variation with different number of reinforcement for extruded specimen. 


\section{Conclusion}

Wear resistance of compacted reinforced aluminum powder has achieved experimentally that the number of reinforcement wires significantly improves it. The hot extrusion process for reinforced aluminum powder increases the bonding between the matrix material (aluminum powder) and the reinforcement ones (copper wires). This process leads in turn to enhancement of ductility, then both hardness and wear resistances get increase and enhance.

\section{References}

[1] Wodarczyk-Fligier, A., Dobrzaski, L.A. and Adamiak, M. (2007) Influence of Heat Treatment on Properties and Corrosion Resistance of Al-Composite. Journal of Achievements in Materials and Manufacturing Engineering, 21, 55-58.

[2] Dobrzaski, L.A., Wodarczyk, A. and Adamiak, M. (2006) Composite Materials Based on EN AW-Al Cu4Mg1(A) Aluminium Alloy Reinforced with the Ti(C,N) Ceramic Particles. Materials Science Forum, 530-531, 243-248. http://dx.doi.org/10.4028/www.scientific.net/MSF.530-531.243

[3] Torres, B., Lieblich, H., Ibanez, J. and Garcia, A. (2002) Escorial, Mechanical properties of some PM Aluminide and Silicide Reinforced 2124 Aluminium Matrix Composites. Scripta Materialia, 47, 45. http://dx.doi.org/10.1016/S1359-6462(02)00095-7

[4] Tjong, S.C. and Mal, Z.Y. (2000) Microstructural and Mechanical Characteristics of in Situ Metal Matrix Composites. Materials Science and Engineering, 29, 49-113. http://dx.doi.org/10.1016/S0927-796X(00)00024-3

[5] Dyzia, M. and leziona, J. (2008) Aluminium Matrix Composites Reinforced with AlN Particles Formed by in Situ Reaction. Archives of Materials Science and Engineering, 31, 17-20.

[6] Yeh, J.W., Yuan, S.-Y. and Peng, Ch.-H. (1998) A Reciprocating Extrusion Process for Producing Hypereutectic Al-20 wt. \% Si Wrought Alloys. Materials Science and Engineering, A252, 212-216. http://dx.doi.org/10.1016/S0921-5093(98)00677-7

[7] Dobrzaski, L.A., Wodarczyk-Fligier, A. and Adamiak, M. (2005) Properties and Corrosion Resistance of PM Composite Materials Based on EN AW-Al Cu4Mg1(A) Aluminum Alloy Reinforced with the Ti(C,N) Particles. Proceedings of 11th International Scientific Conference on the Contemporary Achievements in Mechanics, Manufacturing and Materials Science CAM3S'2005, Gliwice-Zakopane, 289-295.

[8] Dobrzaski, L.A., Wodarczyk-Fligier, A. and Adamiak, M. (2006) Structure and Properties of PM Composite Materials Based on EN AW-2124 Aluminum Alloy Reinforced with the $\mathrm{BN}$ or $\mathrm{Al}_{2} \mathrm{O}_{3}$ Ceramics Particles. Journal of Materials Processing Technology, 175, 186-191. http://dx.doi.org/10.1016/j.jmatprotec.2005.04.031

[9] Jain, R.K. (1980) Production Technology. 15th Edition, AC No. 6219 NSME/SMPD, 8-320.

[10] Pearson, C.E. and Parkins, R.N. (1961) The Extrusion of Metals. 2nd Edition, Chapman and Hall Limited, London, Chapters 2 and 5.

[11] Ruoff, A.L. (1982) Composite Materials. Materials Science, 2, 331-339.

[12] McQueen, H.J., et al. (1986) Strength of Metals and Alloys, Vol. 1. Pergamum Press, Oxford, 761-773.

[13] Rao, M.N. (1994) Hot Extrusion of Sintered Preforms of Aluminium and Aluminium-Iron Composites. Ph.D. Dissertation, Bharathi Dasan University, Tamil Nadu.

[14] Shakespeare, C.R. and Oliver, D.A. (1964) The Hot Extrusion of Metal Powders. International Journal of Powder Metallurgy, 7, 202-212.

[15] Chare, P.J.M. and Sheppard, T. (1969) Powder Extrusion as a Primary Fabricating Process for Al-Fe Alloys. Powder Metallurgy, 12, 109-119.

[16] Hansen, N. (1964) A Note on the Density of Sintered Aluminium Products. Powder Metallurgy Journal, 7, 64-68.

[17] Pérez Delgado, Y., Bonny, K., De Baets, P., Staia, M.H., Neis, P.D., Ferreira, N.F., Malek, O., Vleugels, J. and Lauwers, B. (2013) Friction and Wear Response of Tib2-B4c Ceramics. International Journal Sustainable Construction \& Design, 4.

[18] Mohammed, Y., Moustafa, M.M., Mohamed, A.T. and Abdel-Jaber, G.T. (2014) Finite Element Analysis of Flow Behaviors of Aluminum Powder Compacts. IJARES International Journal of Applied Research in Engineering and Science, 1, 1-10.

[19] Hassan, M.K., Mohammed, Y. and Abu El-Ainin, H. (2012) Improvement of Al-6061 Alloys Mechanical Properties by Controlling Processing Parameters. International Journal of Mechanical \& Mechatronics Engineering, 12, 14.

[20] Constantin, V., Scheed, L. and Masounava, J. (1999) Physics and Chemistry of Tribological Wear. Journal of Tribology, Transactions of the ASME, 121. 